(literally gigaseconds), especially as neither of these are SI units. These are, however, minor criticisms in a text that will be welcomed by both experimenters and theorists. The bibliography of more than 600 references, and the complete author and subject indices, combine to make this a book which will be not only read and enjoyed but consulted again and again.

E. ROLAND DOBBS

\section{THE COLOURS OF THE RAINBOW}

Daylight and its Spectrum

By S. T. Henderson. Pp. $x+277$. (Hilger: London, 1970.) 104s.

DAYLIGHT is part of our common visual experience of the environment and its spectrum is familiar to us all in the rainbow. It is also an important study in many diverse fields. Yet little has been written about it outside the specialist literature. Dr Henderson has made a most welcome contribution by reviewing the work on "Daylight and its Spectrum" in this book-work to which he has himself contributed in recent years.

It would have been a significant achievement to have produced a book for those who have a professional interest in the subject, but the author has produced a book which by its style and typographic design will commend itself to the general reader also. For anybody who has retained a curiosity about his physical environment this book will be found fascinating.

The book commences with introductory chapters on the growth of spectroscopy from ancient ideas of the rainbow to modern spectroscopic methods, the Sun, the Earth's atmosphere, atmospheric scattering and the solar constant. Then follows a chronological account of the work on the daylight spectrum from 1879 to 1968 ; high-altitude measurements; colorimetric measurements of daylight between 1960 and 1968; and the processing

\section{ADVENTURES FOR THE EYES}

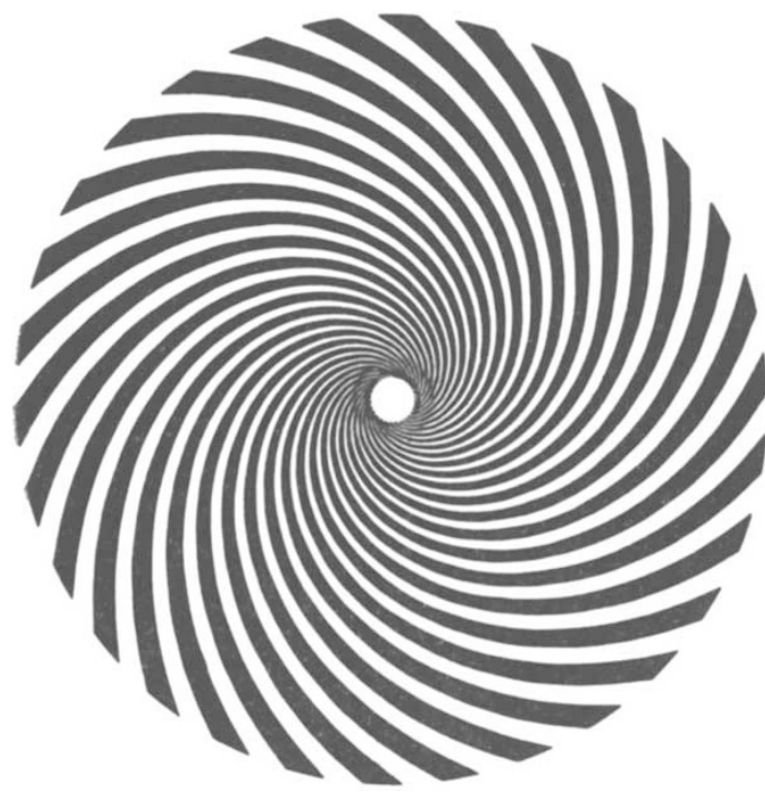

A moiré effect from sixty (alternately black and white) $45^{\circ}$ logarithmic spirals, one of many patterns described in The Science of Moiré Patterns by Gerald Oster, a new and revised edition of which has recently been published (Edmund Scientific Co.: 555 Edscorp Building, Barrington. New Jersey $08007 ; 1969, \$ 3)$. Dr Oster discusses uses for moirés in mathematics, physics, engineering and psychology and, for those who would like to play further with the patterns, there are kits available on request to the publishers. of daylight spectra. A most interesting chapter on less common forms of daylight includes measurements during eclipses, the zodiacal light and other sunlight effects, and the colour of the sky.

Finally, three chapters are devoted to the uses of daylight, the development of artificial sources of daylight and the uses of artificial daylight. The supplementation of, or substitution for, daylight in buildings and problems of colour rendering represent an area within the experience of everybody. A more specialized topic is in colour matching; for example, the lighting conditions under which the dyeing of textiles may be compared and thus controlled.

Appendices provide lists of units and definitions in radiation, light and colour; a chronological list of some sixty contributors to the subject from Anaximenes to Albrecht; and the book finishes with an excellent list of 449 references taken, in the main, up to the end of 1968.

\section{A. HUMPHREYS}

\section{PHYSICS WITHOUT PEDANTRY}

Thermal Physics

By Charles Kittel. Pp. 418. (Wiley: Now York and London, January 1970.) 100s.

Professor Kittel sets an admirable example by writing comparatively elementary textbooks, and one wishes more physicists of his distinction would do the same. His authority shines through all he writes and gives the reader confidence that at the heart of the argument is a real attempt to communicate the art of thinking seriously about physical problems, something more than just another statement of those ideas that are conventionally supposed to be important to students.

In contrast to many treatments of statistical physics, Kittel is more concerned to show the characteristic methods in operation than to discuss their logical foundations. He softens up our resistance by a clear account of a simple soluble problem, and proceeds to ask us to accept that what is demonstrated by the special case is capable of generalization. Before we are aware of what we have granted, we are swept through entropy ("a definition whose simplicity leaves us breathless") and on to the grand partition function, nogative temperature and fluctuations before page 100 is reached. From then on we are exposed to a splendid variety of applications in which thermodynamical and statistical methods are used as team-mates in elucidating the thermal and kinetic properties of gases, metals, white dwarfs, liquid helium, radiation, and electric and magnetic materials. There are large and small exercises scattered through the text, and by the end the student should have a very decent competence in thinking his way through problems in this field. He may even have forgotten, in the enthusiasm of getting the right answer, how much the author imposed on his credulity in the first chapters.

To what extent, one may ask, is this confidence-trick justified? For my part I have very few reservations, because no attempt is made to hide the fact that some awkwardnesses are being swept under the carpet. The student who is worried will have no difficulty, once he has mastered this text, in returning to the foundations with the aid of other books, of which there are many suitable. But perhaps the best reason for taking a lenient view of the logical short cuts is that, from the point of view of the ordinary physicist, this is genuinely not a very difficult subject to get into some sort of tidy shape. With one exception, the fundamental problems that unwise authors agonize over are Gordian knots that are better cut through than meticulously untied-they are material for mathematicians rather than physicists, who will cheerfully assent to all manner of dubious arguments provided nobody claims that it is possible to make them rigorous. The one exception, and the one point where I 